\title{
STUDENT PERSPECTIVES ON THE COVID-19 EMERGENCY REMOTE TEACHING AT A CATALAN ENGINEERING SCHOOL
}

\author{
V. Moreno Oliver, D. Hernández-Leo \\ Universitat Pompeu Fabra (SPAIN)
}

\begin{abstract}
Due to the COVID-19 health crisis, the UPF closed its physical doors in mid-March, in line with all other universities. As a result, all teaching activities (initially conceived as on-site) had to be reorganised in order to fit a new, totally online learning environment. The Teaching Quality and Innovation Support Unit (USQUID) at the UPF Engineering School and ICT Department has provided the students and teachers of the School with support and guidance in many ways, including devising a feedback questionnaire addressed to undergraduate students of the following degrees: Computer Engineering, Audiovisual Systems Engineering, Telecommunications Network Engineering, Mathematical Engineering in Data Science, and Biomedical Engineering. The questionnaire aimed to canvass the views of the students on key aspects of this switch, such as teaching methods used in every course, the management of teamwork, continuous assessment, materials made available, etc. The total number of respondents was 242, distributed as follows: 52 from the degree in Biomedical Engineering (taught in collaboration with another UPF department) and 190 from the ICT degrees.
\end{abstract}

The results show that students do in fact prefer some features of this new way of working. For instance, according to the collected data, the availability of teachers to students (one of the advantages of on-site learning) has been preserved, something students value highly. They also appreciate the way lectures, seminars and practical sessions have been reorganised. On the other hand, results also show that it has been hard for our students to get on with their tasks within the deadlines set, possibly because they are generally not as autonomous and disciplined as the average student at online universities. Another difficulty related to this has been the planning of group activities, which are typically designed to be done on-site and have been necessarily adapted to online learning. We have gathered information and data that reflect how hard it is for group members to attend videoconferences simultaneously or even to form working groups, which has led them to perform tasks individually. These results show the importance of facilitating time slots and learning spaces in order to plan and perform group activities.

This paper presents both the context and the results obtained from the study carried out in the UPF Engineering School and the ICT Department. It includes information on what aspects of online teaching are valued most highly by students with traditional profiles (those enrolled at on-site universities), especially regarding the links between synchronous and asynchronous learning. User pointers arise that may come in useful for the entire university community, in particular designing hybrid formats that will certainly be the educational tools used next year at all universities.

Keywords: Covid-19, e-learning, online learning, remote monitoring, continuous assessment, training digitalisation.

\section{INTRODUCTION}

It is a known fact that the COVID-19 health crisis has had a powerful impact at all levels, including education at all stages [1]. Several educational institutions [2] including UPF, cancelled all on-site classes in mid-March and have worked flat out to reorganise and develop teaching programmes in digital format [3], including their evaluation, monitoring and feedback processes [4,5]. The successful adaptation of teaching programmes initially conceived as on-site is heavily driven by the profile of students and teachers, as well as the resources available. That is why many institutions have been careful to analyse their student's responses to these changes [6].

Students attending on-site universities are generally in the younger age range. According to the report [7], published by the Spanish Ministry of Science, Innovation and Universities, $76.7 \%$ of the students enrolled at on-site universities are aged between 18 and 25 years, and the average age at UPF is 19 years, according to the report [8]. Younger students benefit from greater monitoring, care and guidance during their period of adaptation to university, which is certainly a complex adjustment requiring time and maturity. In contrast, the profile of students at distance education universities is older: students' ages range on average from 30 to 39 years old, and here they typically carry family responsibilities 
and/or are currently working. This profile is also characterised by high motivation and self-discipline since work and domestic commitments require them to be well organised in their studies [9].

Beyond the contrasting features of students enrolled at on-site and distance universities, we also wish to emphasise that the temporary shift to distance education requires the School to take more control over the design of the courses, their development and implementation [10]. In the case of UPF, La Factoria+ and the CLIK (technical and pedagogical units respectively), have designed seven webinars on digital tools for teaching and assessment. These webinars include both technical items and pedagogical recommendations, along with user guides in both document format and as videos to maximise their impact on the target student group. A total of 39 teachers from the UPF Engineering School have participated in at least one webinar. Most of the teaching and research staff at the School were in charge of at least one course. Since the videos are available to view at any time on the University website, the impact of the training goes beyond live attendance at the webinar.

Courses have been adapted to meet the changes: out of 25 courses, there were changes in $67 \%$ of them. These changes have affected contents, methodology and assessment systems. Changes in assessment focused on the percentage of the final grade assigned to each activity (the percentage assigned to continuous evaluation rose compared to that assigned to the final exam). It is also observed that the most widely used method of assessment remains written activities without notes ( $83 \%$ of cases). Finally, it should be noted that online simulators have been used to recreate both synchronous and asynchronous work typical of on-site laboratories.

\section{METHODOLOGY}

To conduct the study, we used a descriptive methodology and collected both qualitative and quantitative data. During the first stage, we focused on a documentary analysis of third-term courses teaching plans, which covered teaching and learning methodologies and assessment. Later, we designed and distributed an anonymous online questionnaire addressed to all the undergraduate students of the School, including those from the bachelor's degrees in Computer Engineering (GEI), Audiovisual Systems Engineering (GESA), Telecommunications Network Engineering (GEXT), Mathematical Engineering in Data Science (GEMCD) and Biomedical Engineering (GEBM). It should be noted that the bachelor's degree in Mathematical Engineering in Data Science (GEMCD) was implemented later. When the study was conducted, the fourth year of this degree had not been implemented yet, so there are no available data for that degree and year.

The student satisfaction questionnaire collected data using both a Likert scale and qualitative assessments. Data were collected in the second half of May. These were the samples collected in each degree:

Table 1. Sampling distribution by degree and year of majority enrolments.

\begin{tabular}{l|c|c|c|c}
\hline \hline & $1^{\text {st }}$ year & $2^{\text {nd }}$ year & $3^{\text {rd }}$ year & $4^{\text {th }}$ year \\
\hline GEBM & 14 & 18 & 11 & 9 \\
\hline ICT degrees (total) & 43 & 82 & \multicolumn{2}{|c}{$50+15=65$} \\
\hline GESA & 19 & 25 & 11 & 2 \\
\hline GEXT & 10 & 9 & 6 & 3 \\
\hline GEI & 5 & 23 & 20 & 10 \\
\hline GEMCD & 9 & 25 & 13 & $*$ \\
\hline \hline
\end{tabular}

Given the characteristics of the bachelor's degrees' syllabus, the data of the first year of the ICT bachelor's degrees were jointly analysed since most of the first-year credits are common for these degrees. The data of the second year of each ICT bachelor's degree were analysed separately since most of the courses are compulsory and specific to each degree. The data of the third and fourth years of the ICT bachelor's degrees were jointly analysed since most of the courses are optional and are offered to students of all the degrees. The data of the bachelor's degree in Biomedical Engineering are analysed separately since its syllabus is substantially different from those of the ICT bachelor's degrees.

The questionnaire started with basic questions to identify data such as the degree and the year of each participant. Then, students were asked to give a mark between 1 and 4 ( 1 being totally unsatisfied and 4 satisfied with all courses) to assess such elements as the adaptation of the third-term courses to online 
learning, digital tools used, the ease of attending synchronous lectures, receiving videos and readings instead of synchronous activities, attending synchronous seminars and practical sessions, having the video recordings of the sessions available to access them from the Learning Management System (LMS), the monitoring and feedback received in the different courses, the materials and resources provided by the teachers of each course, ease of communication with teachers and the quality of communication with their fellow students when working in groups.

Later, a blank field was provided so that students could leave comments on which methodological approach they had preferred in the third-term courses. They were also asked to justify their choice.

Next, they were asked to list up to three general areas for improvement they had detected during the third term. In this case, we highlight comments related to the subject-matter of this paper, that is, distinctive features between on-site and distance education.

Finally, a blank field was provided so students could make any other comment or clarification they wished.

\section{RESULTS}

In this section, we present a synthesis of the most relevant results regarding aspects of online learning that were best-valued by students with a traditional profile, that is, students that had enrolled at an onsite university. Following the same order as the structure of the questionnaire, we focus on the dichotomy between synchronous and asynchronous learning.

\subsection{Satisfaction questionnaire}

Next, we present the results showing student satisfaction regarding the following items:

A. Digital tools used

B. Attending synchronous lectures

C. Receiving videos and readings instead of synchronous activities

D. Attending synchronous seminars and practical sessions

E. Having video recordings of sessions available at the Learning Management System (LMS)

F. Communication with fellow students when working in groups

The statistical values applied are the following: a) Average: the sum of the ratings divided by the total number of them (that is, $n$ ), b) Standard Deviation (dispersion): the measure indicating how dispersed the ratings are with reference to the average and c) mode (central tendency): the most frequent rating in the set of values analysed.

Bachelor's degree in Biomedical Engineering:

Table 2. Results of the satisfaction questionnaire for $1^{\text {st }}$-year students of the bachelor's degree in Biomedical Engineering.

\begin{tabular}{l|c|c|c|c|c|c}
\hline $\begin{array}{c}\text { 1st year } \\
(n=14)\end{array}$ & $A$ & $B$ & $C$ & $D$ & $E$ & $F$ \\
\hline Average & 2.71 & 2.00 & 2.21 & 1.93 & 2.93 & 2.85 \\
\hline Deviation & 0.91 & 0.96 & 1.25 & 0.83 & 1.27 & 0.99 \\
\hline Mode & 3 & 2 & 1 & 2 & 4 & 4 \\
\hline \hline
\end{tabular}

One of the most valued items was "Communication with fellow students when working in groups" $(F)$, with an average rating of 2.85/4, a deviation of 0.99 and a mode of $4 / 4$. "Having the video recordings of the sessions at the LMS" (E) was the item with the highest average rating (2.93/4) and also has a mode of 4/4. However, this item presents the highest deviation (1.27) and, therefore, the greatest dispersion. The item with the lowest average rating (1.93/4) was "Attending synchronous seminars and practical sessions" (D), with a mode of $2 / 4$ and a deviation of 0.83 . 
Table 3. Results of the satisfaction questionnaire for $2^{\text {nd }}$-year students of the bachelor's degree in Biomedical Engineering.

\begin{tabular}{l|l|l|l|l|l|l}
\hline \hline $\begin{array}{c}2^{\text {nd }} \text { year } \\
(n=20)\end{array}$ & \multicolumn{1}{|c|}{$A$} & \multicolumn{1}{|c|}{$B$} & \multicolumn{1}{|c|}{$C$} & \multicolumn{1}{|c}{$D$} & \multicolumn{1}{|c}{$E$} & \multicolumn{1}{c}{$F$} \\
\hline Average & 3.00 & 2.50 & 2.72 & 2.72 & 3.33 & 2.89 \\
\hline Deviation & 0.69 & 0.71 & 0.89 & 1.02 & 0.69 & 0.90 \\
\hline Mode & 3 & 3 & 3 & 3 & 3 & 3 \\
\hline \hline
\end{tabular}

In second year, the ratings were notably higher than in first year. In general terms, the average ratings and the mode were higher, and the deviation, significantly lower. As was the case in first year, the highest-rated item was "Having the video recordings of the sessions at the LMS" (E), with an average of 3.33/4 (that is, students were satisfied with regard to several courses), a deviation of 0.69 (the lowest deviation registered, along with item A's) and a mode of $3 / 4$. The item regarding "Digital tools used" (A) was also very positively valued; specifically, its average was 3.00 , its deviation 0.69 (the lowest one registered) and its mode 3/4. In second year, the item "Attending synchronous seminars and practical sessions" (D) was given notably higher ratings than in first year; specifically, its average rating was 2.72/4, int mode $3 / 4$ and its deviation 1.02 .

Analysis of the data from third and fourth (with a total number of respondents of 11 and 9 , respectively) shows average ratings above $2 / 4$ in all cases, except for the item (C) in fourth year, where this value was 1.75. In both years, the best-valued item was "Having the video recordings of the sessions at the LMS" (E), with an average of 3.10/4 (that is, between several and all of the courses), a deviation of 1.29 and a mode of $4 / 4$ in third year, and an average of 2.63/4, a deviation of 1.29 and a mode of $3 / 4$ in fourth year. In the final years, it should be noted that, although a similar trend to previous years is observed, deviations are higher than 1.00 in all cases, so homogeneity is lower than in the full range of answers.

ICT bachelor's degrees:

Table 4. Results of the satisfaction questionnaire for $1^{\text {st }}$-year students of the ICT bachelor's degrees.

\begin{tabular}{l|c|c|c|c|c|c}
\hline \hline $\begin{array}{c}1^{\text {st }} \text { year } \\
(n=43)\end{array}$ & $A$ & $B$ & $C$ & $D$ & $E$ & $F$ \\
\hline Average & 2.72 & 2.58 & 2.60 & 2.42 & 3.60 & 2.58 \\
\hline Deviation & 0.85 & 1.01 & 0.94 & 0.79 & 0.58 & 0.96 \\
\hline Mode & 3 & 2 & 2 & 3 & 4 & 3 \\
\hline \hline
\end{tabular}

Data collected indicate that the respondents were satisfied with several courses regarding the six items they were asked about. In all cases, the mode was equal to or higher than 2/4. The deviations ranged from 0.58 for the item "Having the video recordings of the sessions at the LMS" (E), which in addition has the highest mode and average (4/4 and 3.60, respectively), and 1.01 for the item (B), "Attending synchronous lectures".

Table 5. Results of the satisfaction questionnaire for $2^{\text {nd }}$-year students of the GESA.

\begin{tabular}{l|c|c|c|c|c|c}
\hline $\begin{array}{c}2^{\text {nd }} \text { year GESA } \\
(\boldsymbol{n}=25)\end{array}$ & $A$ & $B$ & $C$ & $D$ & $E$ & $J$ \\
\hline Average & 2.36 & 1.92 & 2.52 & 2.17 & 2.84 & 2.60 \\
\hline Deviation & 0.91 & 0.81 & 1.05 & 0.96 & 1.03 & 0.96 \\
\hline Mode & 3 & 2 & 3 & 2 & 4 & 2 \\
\hline \hline
\end{tabular}

In second year (GESA), an item was given an average rating slightly lower than 2/4, "Attending synchronous lectures" (B), with an average of $1.92 / 4$, a deviation of 0.81 and a mode of 2 . "Having the video recordings of the sessions at the LMS" $(E)$ is again the item with the highest average rating $(2.84 / 4)$ and mode (4/4). 
Table 6. Results of the satisfaction questionnaire for $2^{\text {nd }}$-year students of the GEXT.

\begin{tabular}{l|c|c|c|c|c|c}
\hline $\begin{array}{c}2^{\text {nd }} \text { year } \\
\text { GEXT } \\
(n=10)\end{array}$ & $A$ & $B$ & $C$ & $D$ & $E$ & $F$ \\
\hline Average & 2.44 & 1.88 & 1.56 & 1.67 & 3.11 & 2.78 \\
\hline Deviation & 0.73 & 0.83 & 0.88 & 0.87 & 1.05 & 1.39 \\
\hline Mode & 3 & 2 & 1 & 1 & 4 & 4 \\
\hline \hline
\end{tabular}

Data of GEXT's second year show that half of the items were given an average rating under $2 / 4$ and the mode was $1 / 4$ in two cases. These items were "Attending synchronous lectures" (B), "Receiving videos and readings instead of synchronous activities" (C) and "Attending synchronous seminars and practical sessions" (D). The best-valued item was again "Having the video recordings of the sessions at the LMS" $(E)$, with an average of $3.11 / 4$, a deviation of 1.05 and a mode of 4 .

Table 7. Results of the satisfaction questionnaire for $2^{\text {nd }}$-year students of the GEl.

\begin{tabular}{l|c|c|c|c|c|c}
\hline \hline $\begin{array}{c}2^{\text {nd }} \text { year GEI } \\
(\boldsymbol{n}=23)\end{array}$ & $A$ & $B$ & $C$ & $D$ & $E$ & $F$ \\
\hline Average & 2.17 & 2.61 & 1.68 & 2.61 & 3.48 & 3.04 \\
\hline Deviation & 0.83 & 0.99 & 0.84 & 0.78 & 0.79 & 0.93 \\
\hline Mode & 3 & 3 & 1 & 2 & 4 & 4 \\
\hline \hline
\end{tabular}

In GEl's second year the ratings were notably higher than in GEXT's. Indeed, the best-rated item was once again "Having the video recordings of the sessions at the LMS", with an average of 3.48/4, a deviation of 0.79 and a mode of 4 . The second best-rated item was "Communication with fellow students when working in groups" $(F)$, with an average of 3.04 , a deviation of 0.93 and a mode of $4 / 4$. As was the case in GEXT's second year, "Receiving videos and readings instead of synchronous activities" (C) was the worst valued item, with an average of $1.68 / 4$, a deviation of 0.84 and a mode of $1 / 4$, which was a unique value in this set.

Table 8. Results of the satisfaction questionnaire for $2^{\text {nd }}$-year students of the GEMCD.

\begin{tabular}{l|c|c|c|c|c|c}
\hline \hline $\begin{array}{c}2^{\text {nd }} \text { year } \\
\text { GEMCD }(n=26)\end{array}$ & $A$ & $B$ & $C$ & $D$ & $E$ & $F$ \\
\hline Average & 2.64 & 2.60 & 1.68 & 2.68 & 3.56 & 3.16 \\
\hline Deviation & 0.76 & 0.82 & 0.63 & 0.95 & 0.77 & 0.90 \\
\hline Mode & 3 & 3 & 2 & 3 & 4 & 4 \\
\hline \hline
\end{tabular}

Data from GEMCD's second year show a level of satisfaction similar to GEl's. Only one item, "Receiving videos and readings instead of synchronous activities" (C), was given an average rating lower than 2 . This item had also the lowest mode: $2 / 4$, a unique value in the set.

As with GEXT and GEl's second year, "Having the video recordings of the sessions at the LMS" (E) was one of the items best handled in the respondents' view. The item was highly rated in several or all of the courses and was given an average of 3.56, a deviation of 0.77 and a mode of 4 . The second best-valued item was "Communication with fellow students when working in groups" $(F)$, with an average of 3.16, a deviation of 0.90 and a mode of $4 / 4$.

Regarding data of ICT bachelor's degrees' third and fourth years, the item "Having the video recordings of the sessions at the LMS" (E) stands out again with an average of 3.28 , a deviation of 0.94 and a mode of 4 . The rests of items were given an average rating and a mode higher than 2.10.

\subsection{Information additional to the ratings above}

As previously indicated, a blank field was provided to enable the participants to give additional information as a means of supplementing the data and ratings collected. In total, 25 comments were 
collected from students of the Bachelor's degree in Biomedical Engineering and 60 from students of ICT engineering degrees. The distribution of the comments by virtue of the highlighted item is detailed below.

In both cases, students made comments referring explicitly to key features between on-site and distance education. Specifically, the respondents enjoyed being able to attend all sessions in synchronous format and being able to access these once finished via the LMS (30\% of the comments by Biomedical Engineering students and $21 \%$ of the comments by students of ICT degrees).

\subsection{Methodological combinations and formulae best valued by students of the third-term courses}

In this section, we present the results collected in terms of the methodologies best valued by students during the third term. The results shown are differentiated between degrees (Biomedical Engineering and ICT degrees).

\section{Bachelor's degree in Biomedical Engineering:}

First-year students $(n=9)$ appreciated the use of short assessment activities to check that they were keeping up with the course and the fact that the course contents were explained using videos (lasting less than 1 hour) by means of tools such as digital blackboards or PowerPoint presentations. They also appreciated assessment systems in which partial exams marks were taken into account only if they were higher than the final exam mark.

Second-year students $(n=15)$ highlighted fluent and constant communication with teachers, the existence of multiple assessment activities, online availability of videos of all synchronous sessions, so as to be able to revise them at any time via tools such as Collaborate, and the fact that examiners had now given greater weight to continuous assessment over final exams.

Third-year students $(n=6)$ valued positively their teachers' close engagement and availability. They also considered that having synchronous classes and making available the corresponding videos later at Aula Global (UPF's Moodle) was a good teaching formula. This fact was also highlighted by fourthyear students $(n=4)$, who emphasised that this resource makes it easier to clear up doubts later, once the video contents have been worked on autonomously, beyond the synchronous session.

ICT bachelor's degrees:

First-year students $(n=17)$ valued positively the fact that sessions were synchronous, recorded and made available online. They also appreciated live feedback from teachers. One of the tools they highlighted was draw.io, used to explain concepts in lectures and seminars. They also consider continuous assessment an advantage.

We will discuss second-year students $(n=53)$ separately by degrees. Second-year students of GESA appreciated the fact that lectures were shorter than one hour and consisted either of synchronous sessions or videos to be watched before the lectures. In addition, they enjoyed being able to use the tool Piazza for problem-solving as well as the switch in assessment, attaching more weight to continuous assessment. Second-year students of GETX spotlight the fact that the sessions were synchronous and made available at Aula Global. They also highlight the fact that sessions lasted less than 1.5 hours. Similarly, second-year students of GEI highlight that the sessions were shorter and recorded and could be uploaded for revision at any time. Second-year students of GEMCD spotlight that lectures, seminars and practical sessions were synchronous and very interactive. They also highlight the fact that the sessions were recorded and uploaded to Aula Global.

Finally, third- and fourth-year students $(n=35)$ appreciated flexibility regarding deadlines in some courses, the dynamic style in classes where participation is very high and the fact that the sessions were synchronous and made available at Aula Global. In addition, they highlight the proper functioning of tools such as Collaborate or Piazza.

\subsection{Areas for improvement}

Next, the students were asked to indicate up to three areas for improvement that they had detected in general terms during the third term. The data collected in this section synthesise the responses related to the scope of this paper, that is, items highlighted by the students regarding differences in the learning process between on-site and distance teaching.

Bachelor's degree in Biomedical Engineering: 
Many different students from all years, specifically, 7 first-year, 13 second-year, 7 third-year and 6 fourthyear students, stress the importance of good communication between teachers and students regarding the organisation and development of distance learning, a point which reflects a certain longing for human contact and direct (on-site) interaction with teachers in the classroom.

ICT bachelor's degrees:

First-year students $(n=16)$ insist on recording and uploading all the sessions. Let us remember that this item was very positively valued by all students.

Second-year students $(n=52)$ indicated different areas. Those of GESA, GEI and GEXT commented on the need to attach more weight to partial and continuous submissions. In line with these comments, students of GEI and GEMCD emphasised that the coordination between courses should be maximised in order to prevent a great number of submissions taking place at the same time. Second-year students of GESA proposed that the duration of classes duration should be shortened, which was backed up by third- and fourth-year students $(n=39)$.

\subsection{Comments or general clarifications}

The questionnaire concluded with a blank field so that students could make any other comment or clarification. In total, 15 comments were collected from students of the bachelor's degree in Biomedical Engineering and 56 from students of ICT degrees. In both cases, students used this blank field to insist on items that had already been collected throughout the questionnaire and presented in previous sections, such as the fact that synchronous sessions were recorded, and the corresponding videos uploaded to enable access at any time.

\section{CONCLUSIONS}

This study consisted of two phases: a) a documental review of the teaching plan to analyse, guarantee and give advice on the relevant methodological and assessment changes to third-term courses due to the health emergency, and b) a subsequent data and information collection in the form of a questionnaire addressed to students, giving them the opportunity to answer questions and give comments on areas for improvement. The results obtained showed which aspects of online learning were best valued by our students, who, let us remember, have a traditional profile, as they are enrolled at an on-site university.

- One of the main advantages of on-site learning according to the respondents (and something they have missed) is the closeness between teachers and students since they feel that this kind of communication offers better monitoring of their learning process. This conclusion aligns with the disadvantages of online learning that have been highlighted in works such as [11] who also list items such as impersonal communication and lack of direct contact. In this regard, other elements should be noted too, such as the lack of the teleworking habit, both in teachers and students since all syllabi were originally designed for an on-site basis.

- It should be noted that, despite missing on-site activities and human contact, students have valued this new adaptation to the online format positively. In other words, because of either teachers' availability or the way the different lectures, seminars and practical sessions have been structured, the students have continued to feel their teachers' close engagement throughout the term. However, some mentioned as an area for improvement the activities and seminars and practical sessions aiming to work in groups, in collaboration with their fellows. This could seem to contradict the quantitative results collected since, broadly, respondents from all the years and bachelor's degrees have valued positively the communication with their fellow students in most of the courses. It should be borne in mind that our students are used to working collaboratively with their fellows and they value the outcomes of this practice very positively, which has been noted by different authors [12]. Especially, they enjoy having the time and space for this kind of work, something which has been lost due to the unforeseen situation caused by the pandemic.

- It emerges that the digitalisation of education has improved on some of the drawbacks of the onsite model, which has been stated by authors such as [13, 14]. For example, in the on-site model, the learning lasts as long as the class itself, and there is no chance to attend the class again once it has finished. Thanks to the new online format, many students are enjoying the chance to view the sessions recorded and uploaded at the institutional LMS, which means they can be consulted at any time. This significantly increases inclusion and flexibility in the broadest terms, as has been proved by studies such as [15]. 
- Another fact reconfirmed by this study is the cardinal importance of feedback in the learning process, something which is even more important in the distance format.

- Online distance learning can lead to frustrating and overwhelming situations for students since, occasionally, there are audio problems with videocalls, the recording breaks down or sessions are too long. In this study, we have collected comments on aspects such as the duration of sessions.

- These conclusions open the door to reflections on a hybrid model designed with time and tools enough to combine the strengths of both formats (on-site and distance learning), paying particular attention to the items highlighted by the students themselves in this study, as well as to factors noticed by the School Direction and others shared with the teachers.

\section{ACKNOWLEDGEMENTS}

This study has been conducted within the framework of the PlaCLIK Project (UPF aid programme for projects on teaching quality and innovation). We would like to thank Helena Martínez, support staff, for her collaboration in the project as well as the students that took part by responding to our questionnaire.

\section{REFERENCES}

[1] L. Albó, M. Beardsley, J. Martínez-Moreno, P. Santos, D. Hernández-Leo, D, "Emergency Remote Teaching: Capturing Teacher Experiences in Spain with SELFIE", European Conference on Technology-Enhanced Learning, vol. 12315, pp. 318-331, 2020.

[2] A.M. Cauce, Novel coronavirus information. University of Washington, 2020. Retrieved from https://www.washington.edu/coronavirus/2020/03/06/beginning-march-9-classes-and-finals-willnot-be-held-in-person-message-to-students/

[3] J. Crawford, K. Butler-Henderson, R. Jurgen, B. Malkawi, M. Glowatz, R. Burton, P. Magni \& S. Lam, "COVID-19: 20 countries' higher education intra-period digital pedagogy responses", Journal of Applied Learning \& Teaching, vol. 3, no, 1, 2020.

[4] G.S. Pisano, Sadun, R. \& M. Zanini, "From Lessons from Italy's Response to Coronavirus", Harvard Business Review, 2020. Retrieved from https://hbr.org/2020/03/lessons-from-italys-response-tocoronavirus

[5] L. Sun, Y. Tang \& W. Zuo, "Coronavirus pushes education online”, Nature, vol.19, no, 687, 2020.

[6] I. Kamarianosi, A. Adamopoulou, H. Lambropoulos \& G. Stamelos, G, "Towards an understanding of university students' response in times of pandemic crisis (covid-19)", European Journal of Education studies, 2020. Retrieved from https://www.oapub.org/edu/index.php/ ejes/article/ view/ 3149/5786

[7] Spain Goverment, "Datos y Cifras del Sistema Universitario Español", 2020. Retrieved from https://www.ciencia.gob.es/stfls/MICINN/Universidades/Ficheros/Estadisticas/Informe_Datos_Cifr as_Sistema_Universitario_Espanol_2019-2020.pdf

[8] Pompeu Fabra University, "Accés i matrícula als graus de la UPF, curs 2018-2019”, 2019.

[9] Telefónica, "Formación online o presencial: ¿cuál es mejor? - Tendencias", 2020. Retrieved from https://www.telefonicaeducaciondigital.com/tendencias/-/asset_publisher/GOLheSHQiynX/ content/formacion-online-o-presencial-cual-es-mejor-

[10] C. Hodges, S. Moore, B. Lockee, T. Trust \& A. Bond, "The Difference Between Emergency Remote Teaching and Online Learning", Educase, 2020. Retrieved from https://er.educause.edu/articles/2020/3/the-difference-between-emergency-remote-teaching-andonline-learning\#fn1

[11] V. Marín Díaz, E. Reche Urbano \& G.A Maldonado Berea, "VENTAJAS E INCONVENIENTES DE LA FORMACIÓN ONLINE", Revista Digital De Investigación En Docencia Universitaria, vol 7(1), pp. 33-43, 2013.

[12] R.A. Ellis, P. Ginns \& L. Piggott, "E-learning in higher education: some key aspects and their relationship to approaches to study", 2007. Retrieved from https://www.tandfonline.com/doi/full/10.1080/07294360902839909 
[13] J. Cabero, "La investigación en educación a distancia en los nuevos entornos de comunicación telemáticos", International Journal of Social Escientes \& Humanities, vol. XVIII (2), pp. 13-34, 2008.

[14] J.Salinas, "Cambios metodológicos con las TIC. Estrategias educativas y entornos virtuales de enseñanza-aprendizaje”, Bordón, vol. 56(3/4), pp. 469-480, 2004.

[15] D. Gallego \& C. Alonso, "La educación a distancia en los nuevos contextos socioeducativos" in Tecnología educativa (McGraw-Hill), pp. 195-217, Madrid, 2007. 